\title{
ASSESSMENT OF TOTAL ATMOSPHERIC DEPOSITIONS (TAD) IN AKURE, ONDO STATE, NIGERIA
}

\author{
Francis Olawale ABULUDE * \\ Department of Chemistry, Federal University of Technology, Minna, Science and Education Development Institute, Akure, \\ Nigeria, e-mail: walefut@gmail.com \\ Mohamed Mohamed NDAMITSO \\ Department of Chemistry, Federal University of Technology, Minna, Nigeria, \\ e-mail: fudabinda@gmail.com \\ Aishat ABDULKADIR \\ Department of Geography, Federal University of Technology, Minna, Nigeria, \\ e-mail: abuzaishatu@ futminna.edu.ng
}

Citation: Abulude F.O., Ndamitso, M. M., \& Abdulkadir A. (2019). Assessment of Total Atmospheric Depositions (TAD) in Akure, Ondo State, Nigeria. Analele Universită ii din Oradea, Seria Geografie, 29(2), 46-51. https://doi.org/10.30892/auog.292105-791

\begin{abstract}
The aim of the study was to evaluate the TAD of Akure, Ondo State, Nigeria. In this study, rainwater samples were collected monthly in a polyethylene container attached to a funnel for a period of twelve (12) months at 40 designated sites (residential, industrial, and traffic-related areas). The rainwater samples were filtered, the masses of TAD on the filter paper were determined gravimetrically, and atmospheric deposition rates were calculated. Meteorological data were measured at a monitoring site at the Department of Meteorology, Federal University of Technology, Akure, Ondo State, Nigeria. From the results obtained in this study, it was observed that deposition rated ranged between 5 and $427 \mu \mathrm{g} / \mathrm{m}^{2}$. The average temperatures, wind speed, relative humidity, rainfall and wind direction for the periods were $25.00^{\circ} \mathrm{C}, 0.63 \mathrm{mph}, 83.74 \%, 0.03 \mathrm{~mm}$ and $117.43^{\circ} \mathrm{C}(2015)$ and $26.2{ }^{\circ} \mathrm{C}$, $0.74 \mathrm{mph}, 81.89 \%, 0.92 \mathrm{~mm}, 118.32^{\circ}$ (2016). There were relationships between TAD and meteorological parameters. The results showed that TAD in many parts of the studied areas exceeded the World Health Organization guideline standards $\left(350 \mu \mathrm{g} / \mathrm{m}^{2}\right)$.
\end{abstract}

Key words: Air pollution, urbanization, mega cities, gravimetrical, limit,

$$
* \quad * \quad * \quad * \quad * \quad *
$$

\section{INTRODUCTION}

The global air quality is worsening to an alarming rate. Population growth, anthropogenic activities, increase in vehicular movement, land use development, industrialization, and urbanization severely affect the air quality. One of the requirements of living things is clean air, especially human (Herman, 2009; Ndamitso et al., 2016). Despite the efforts in the introduction of

\footnotetext{
* Corresponding Author
} 
cleaner technologies and tighter emission controls in different countries, air pollution remains a major health risk. Also, TAD reduces atmospheric visibility and affects the state of different cultural heritages (Van Grieken and Delalieux, 2004). According to the IPCC (2001), on a global scale, TAD influences the Earth's radiation energy balance, which can impact on global climate change (Tasic et al., 2008).

During raining seasons, particles in the air are either aggregated or dissolved. When atmospheric deposition occurs, dry and wet depositions take place (Puente et al., 2013). Dry deposition of particles takes place by direct impact and gravitational settling on land or water surfaces, while in wet deposition, aerosols and gases are dissolved or suspended in water droplets or ice crystals (Azimi et al., 2003). According to Abulude (2006), atmospheric dust is a problem in Nigeria therefore, it needs attention.

Akure is an urban state capital in Nigeria and so has a steady growth in industrialization and urban development. The record of TAD in Akure, Ondo State has not been explored yet and documented well. According to Furuuchi et al., (2010), in order to employ effective methodologies for controlling or reducing environmental loads, it is important to know the status of air pollution and contributions from emission sources. To allay the fear of air pollution, it will be necessary to conduct this study. The objective of this study was to validate monthly sampling procedure in the sampling locations, focusing on the assessment of total atmospheric deposition. During the twelve months, the atmospheric fallout was obtained monthly.

\section{MATERIALS AND METHODS}

\section{SAMPLING AREA}

The samples were collected in Akure, Ondo State, Nigeria (N07 ${ }^{\circ} 15^{\prime} 46.2^{\prime}{\mathrm{E} 005^{\circ}}^{\prime} 14^{\prime} 29.1 \pm 9 \mathrm{ft}$ ). Samples were collected for a period of twelve (12) months (July 2015 to June 2016). Figure 1 depicted the map of the location.

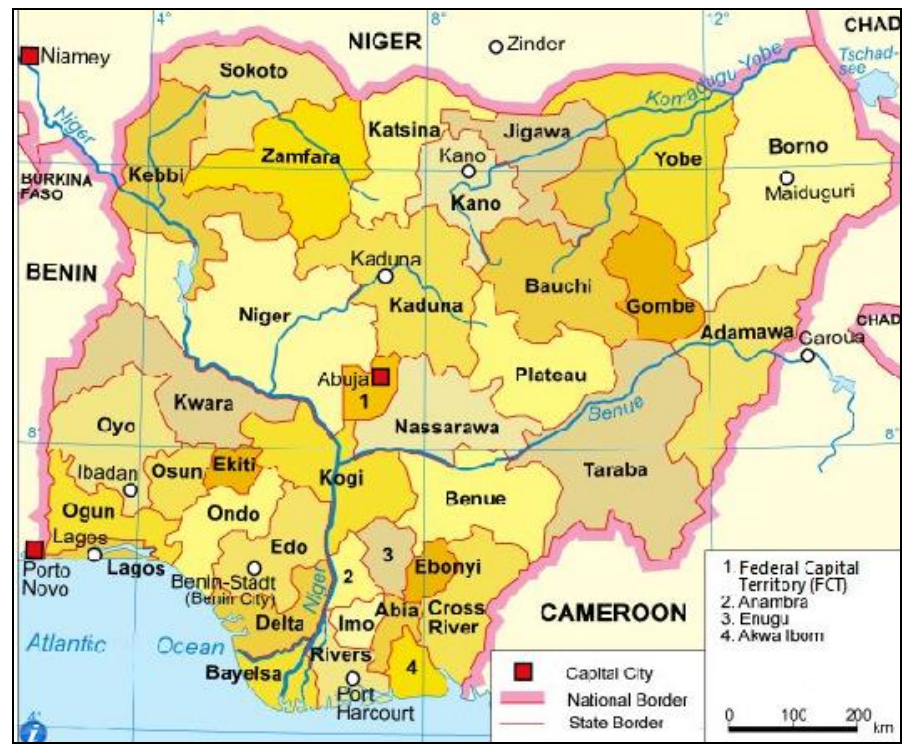

Figure 1. Map of Study Area

\section{SAMPLE COLLECTION}

The aim of the study was to analyze the TAD in Akure, Ondo State, Nigeria. Standard methods used by Onwudiegwu et al. (2016) was employed. Eleven locations were identified with a total of 40 sites. The choice of the locations was based on the followings: industrial, high traffic 
density, road construction, and residential (control). The sampler was placed at each site at a height of 1.5 meters above the ground level. A total of 480 samples was collected at a monthly interval, plastic funnels thoroughly washed into the plastic container with de-ionized water, filtered with Whatman Ashless filter paper, dried in a ventilated oven, and weight determined. Deposition rates were calculated. TAD volumes were obtained using a measuring cylinder before and after days of exposure.

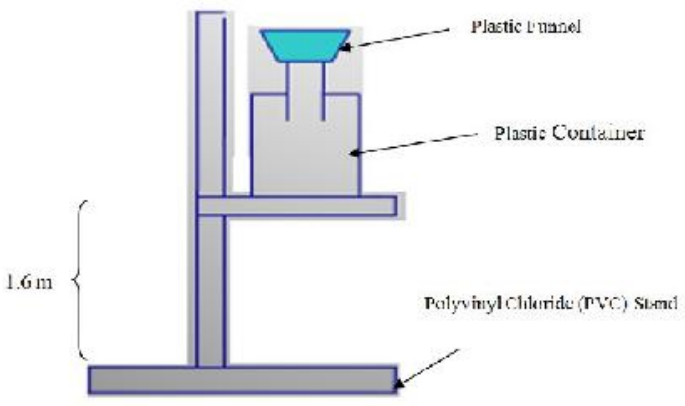

Figure 2. Diagram of locally assembled TAD gauge (Onwudiegwu et al., 2016)

\section{Meteorological Data}

The meteorological data used for the study was obtained from Department of Meteorology, School of Earth \& Mineral Sciences, Federal University of Technology, Akure, Ondo State, Nigeria.

\section{Statistical Analysis}

Minitab 16 Statistical Software was used in the statistical analyses.

\section{RESULTS AND DISCUSSION}

The meteorological data (Air temperature, rainfall, wind speed and direction and humidity) in this study are shown in table 1 . The average temperatures, wind speed, relative humidity, rainfall and wind direction for the periods was $25.00^{\circ} \mathrm{C}, 0.63 \mathrm{mph}, 83.74 \%, 0.03 \mathrm{~mm}$ and $117.43^{\circ}$ (2015) and $26.20^{\circ} \mathrm{C}, 0.74 \mathrm{mph}, 81.89 \%, 0.92 \mathrm{~mm}, 118.32^{\circ}$ (2016). From the results, it was observed that the rainfall for these periods was scanty, the humidity was relatively high and the wind speed was low. Ideally, TAD in air surfaces could be washed off by rain or blown off by wind (Habitable Planet, accessed 2017). In the comparison of TAD collected in the different environmental conditions depicted that rainfall and winds could not dissolve a considerable proportion of TAD in the air during the seasons. Rainfall or wind had a high kinetic energy that could dissolve or remove many particles in the air. Air pollution is strongly affected by temperature, pressure, and humidity, and other meteorological parameters. An example is when winds transport some pollutants from their sources across national boundaries and even across the oceans. Rain transports atmospheric pollutants to earth. Temperature inversions cause Smog when air near the Earth's surface is colder than air aloft. Also, temperature inversions reduce vertical mixing and trap pollutants near Earth's surface. Stagnation events by low winds are rampant during the dry season and could lead to the accumulation of pollutants over several days. These scenarios were the reasons for the high TAD values obtained. The results of TAD observed in this study, were comparable to those recorded by Onwudiegwu et al. (2016).

The results ( 5 to $527 \mu \mathrm{g} / \mathrm{m}^{2}$ ) of this study depicted in figure 2 , showed that part of the TAD value recorded exceeded the recommended limit $\left(350 \mu \mathrm{g} / \mathrm{m}^{2}\right)$. The highest values were observed in the months of November 2015 to February 2016. During these periods there were scanty or no rainfall. The humidity was high, which aided the depositions. Also, higher values could be as a result of strong wind blown from the areas of the construction sites and high traffic density. The 
incidence of TAD on the environ had significant effects on the residents due to complaints of low visibility and dust depositions on buildings, vehicles, and crops. In comparison, of this study results with those obtained by Obioh et al. (2013) for Nigerian mega cities, it was observed that the values of the cities like Aba $\left(422-926 \mu \mathrm{g} / \mathrm{m}^{2}\right)$, Maiduguri $\left(37-370 \mu \mathrm{g} / \mathrm{m}^{2}\right)$ and Kano $(61-757$ $\mu \mathrm{g} / \mathrm{m}^{2}$ ) were far above the results of this study. The reasons for the differences could be attributed to the higher traffic densities of the study areas, again Maiduguri and Kano are closer to Saharan desert, which is closer to dust. Again, the occurrence Harmattan occasioned by the northeast trade winds with dust haze caused dryness and the increase in the erection of buildings and urban growth may contribute to the increased levels TAD in the dry months.

Figure 2 shows the boxplot results of the samples in the periods of study. The Boxplots in this study were used to compare the distributions of PM in the various months and years. The months of July - November 2015 the boxplots were skewed to the right. Only December was symmetrical because the line on the box was close to the center. The whisker lengths were the same. The boxplots of the months of January, April, May, and June were symmetrical, while those of February and March 2016 were skewed to the right. The reason for the skewing to the right was that there were large variations in the values of TAD recorded for the months.

According to Streit and Gehlenborg, (2014), boxplot is known as 'box-and-whiskers plots' in a visual display, boxplot is made up of the minimum, the maximum, the median, the upper quartile, and the lower quartile. The box is rectangular and has the two quartiles (Minimum (lower) and maximum (upper)) at both ends. The length of the box is the interquartile range. At the median, a line is drawn across the box. Boxplots are can be freely drawn in different orientations. The height is the length of the box, which is the indication of sample variability. The place where the sample is centered is depicted with a line across the box.

Table 1. Meteorological data of the study area

\begin{tabular}{|c|c|c|}
\hline \multirow{2}{*}{ Parameters } & \multicolumn{2}{|c|}{ Average } \\
\cline { 2 - 3 } & $\begin{array}{c}\mathbf{2 0 1 5} \\
\text { July - December }\end{array}$ & $\begin{array}{c}\mathbf{2 0 1 6} \\
\text { January - June }\end{array}$ \\
\hline Air Temperature $\left({ }^{\circ} \mathrm{C}\right)$ & 25.00 & 26.20 \\
\hline Wind Speed $(\mathrm{mph})$ & 0.63 & 0.74 \\
\hline Relative Humidity $(\%)$ & 83.74 & 81.89 \\
\hline Rainfall $(\mathrm{mm})$ & 0.03 & 0.92 \\
\hline Wind Direction $\left({ }^{\circ}\right)$ & 117.43 & 118.32 \\
\hline
\end{tabular}

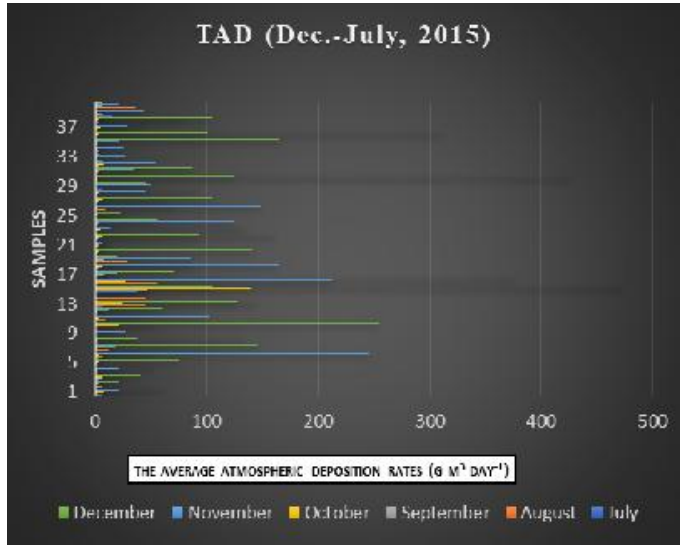

Figure 3. TAD for the months of Dec - July, 2015

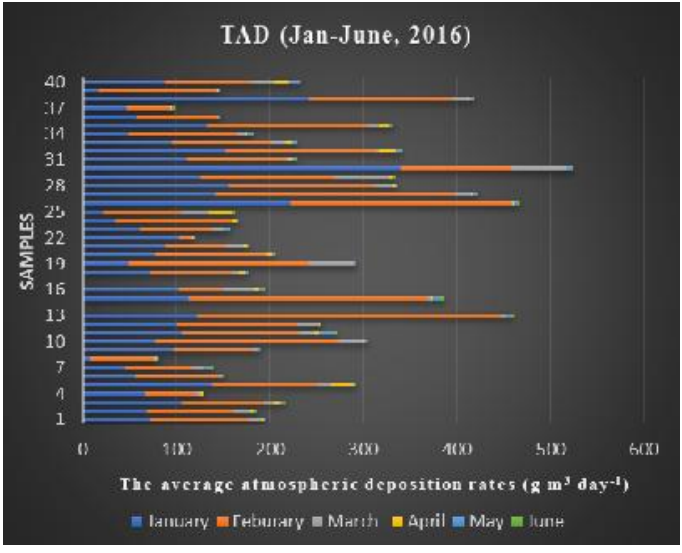

Figure 4. TAD for the months of Jan - June, 2016 


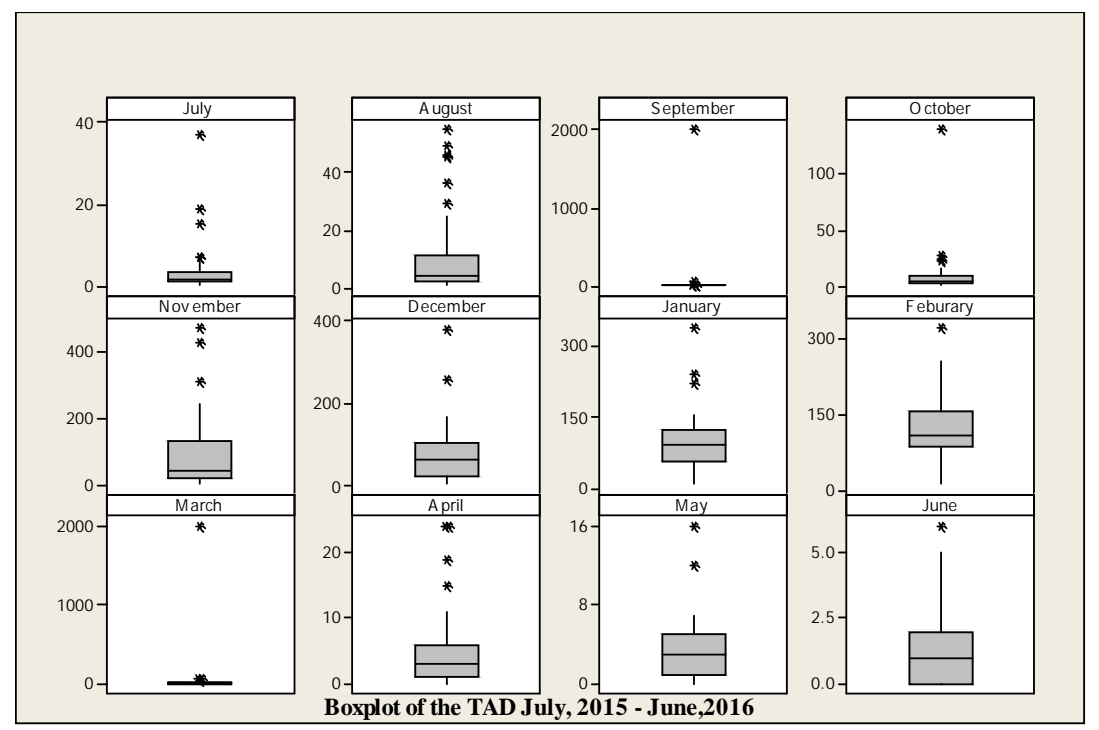

Figure 5. Boxplot of the TAD July, 2015 - June, 2016

\section{CONCLUSION}

No doubt some TAD values were high and there were relationships between TAD and meteorological data of the environ. Man-made activities in Akuremay have contributed to TAD. An awareness should be created on the potential danger of air pollution to the citizenry. The results obtained in this study would assist in the clean air programs in the area. Further research is ongoing to determine the metal concentrations in both rainwater and TAD samples obtained in Akure.

\section{Acknowledgment}

The authors are grateful to the HOD and Mr. Ladipo of the Department of Meteorology, School of Earth \& Mineral Sciences, Federal University of Technology, Akure, Ondo State, Nigeria for the provision of meteorological data.

\section{REFERENCES}

Abulude, F. O. (2006). Analysis of suspended air particulates along four sawmills in Nigeria during the wet and dry seasons. Journal of Engineering and Applied Sciences, 1(3), 224-226.

Azimi, S., Ludwig, A., Thévenot, D. R., \& Colin, J. L. (2003). Trace metal determination in total atmospheric deposition in rural and urban areas. Science of the Total Environment, 308(1-3), 247-256.

Furuuchi, M., Eryu, K., Nagura, M., Hata, M., Kato, T., Tajima, N., ... \& Otani, Y. (2010). Development and performance evaluation of air sampler with inertial filter for nanoparticle sampling. Aerosol Air Qual. Res, 10, 185-192.

Habitable Planet accessed 2017. Atmospheric Pollution: Unit 11. www.learner.org

Herman, G. V. (2009), Omul şi modificările antropice din Câmpia Someşului [The man and anthropogenic changes in Somes Plain], Editura Universității din Oradea, Oradea, Romania.

IPCC, 2001. Climate Change 2001: The Scientific Basis. Contribution of Working Group I to the Third Assessment Report of the Intergovernmental Panel on Climate Change [Houghton, J.T., Y. Ding, D.J. Griggs, M. Noguer, P.J. van der Linden, X. Dai, K. Maskell, and C.A. Johnson (eds.)]. Cambridge University Press, Cambridge, United Kingdom, and New York, NY, USA, 881pp.

Ndamitso, M. M., Abdulkadir, A., Abulude, F. O. (2016). Total atmospheric deposit source apportionment: a review. Environmental Skeptics and Critics, 5(4), 63-78.

Obioh, I. B., Ezeh, G. C., Abiye, O. E., Alpha, A., Ojo, E. O., \& Ganiyu, A. K. (2013). Atmospheric particulate matter in Nigerian megacities. Toxicological \& Environmental Chemistry, 95(3), 379-385. 
Onwudiegwu, C. A., Ezeh, G. C., \& Obioh, I. B. (2015). Trace metals in total atmospheric depositions (TAD) of a Nigerian Island. Journal of Atmospheric Pollution, 4(1), 15-22.

Puente, M., Fernández-Olmo, I., \& Irabien, A. (2013). Variability in metal deposition among industrial, rural and urban areas in the Cantabria Region (Northern Spain). WIT Transactions on Ecology and the Environment, 174, 245-254.

Streit, M., \& Gehlenborg, N. (2014). Points of view: bar charts and box plots. Nature Methods. $11,117$. doi:10.1038/nmeth.2807.

Tasic, M., Rajsic, S., Tomasevic, M., Mijic, Z., Anicic, M., Novakovic, V., ... \& Joksic, J. (2008). Assessment of air quality in an urban area of Belgrade, Serbia. In Environmental Technologies. IntechOpen.

Van Grieken, R., \& Delalieux, F. (2004). X-ray spectrometry for air pollution and cultural heritage research. In Invited lectures: $5^{\text {th }}$ General Conference of the Balkan Physical Union, BPU-5, $25-29$ August 2003, Vrnjačka Banja, Serbia and Montenegro/Jokić, Stevan [edit.] (pp. 234-246).

Submitted:

August 15, 2018
Revised:

May 20, 2019
Accepted and published online July 29, 2019 